Research Article

\title{
Sexual and Reproductive Health Services Utilization among Wolaita Sodo University Students, Ethiopia: A Mixed Method Approach
}

\author{
Muluken Gunta, ${ }^{1}$ Temesgen Tantu $\mathbb{D},{ }^{2}$ Sintayehu Wolka, ${ }^{3}$ Mengistu Meskele $\mathbb{D}^{\mathbb{D}},{ }^{4}$ \\ Asaminew Ayza, ${ }^{1}$ and Bereket Duko $\mathbb{1}^{5,6}$ \\ ${ }^{1}$ Wolaita Zone Health Department, Wolaita Sodo, Ethiopia \\ ${ }^{2}$ Department of Obstetrics and Gynecology, Wolkite University, Wolkite, Ethiopia \\ ${ }^{3}$ Health System Strengthening Special Support Directorate, Federal Ministry of Health, Addis Ababa, Ethiopia \\ ${ }^{4}$ School of Public Health, College of Health Science and Medicine, Wolaita Sodo University, Wolaita Sodo, Ethiopia \\ ${ }^{5}$ Faculity of Health Sciences, College of Medicine and Health Sciences, Hawassa University, Hawassa, Ethiopia \\ ${ }^{6}$ Curtin School of Population Health, Curtin University, Perth, Australia
}

Correspondence should be addressed to Bereket Duko; berkole.dad@gmail.com

Received 6 August 2021; Accepted 8 December 2021; Published 17 December 2021

Academic Editor: Carlo Eduardo Medina-Solis

Copyright (c) 2021 Muluken Gunta et al. This is an open access article distributed under the Creative Commons Attribution License, which permits unrestricted use, distribution, and reproduction in any medium, provided the original work is properly cited.

\begin{abstract}
Background. Youths have been facing different sexual and reproductive health problems such as HIV infections and unplanned pregnancies. Therefore, this study aimed to assess reproductive health services utilization and their associated factors among Wolaita Sodo University students in Wolaita Sodo, Ethiopia. Methods. We conducted an institutionally-based mixed-method study among 759 regular undergraduate university students. Multistage random sampling and purposive sampling techniques have been used to recruit students for the quantitative and qualitative studies, respectively. A pretested self-administered questionnaire was used to collect the data. A logistic regression model was used for quantitative data analysis, whereas thematic analysis was used for qualitative data. We used open-code software-assisted qualitative data analysis. The statistical significance was declared at a $P$ value less than 0.05. Results. We found that 378 (49.8\%) (95\% CI: 46.20-53.34) of respondents had utilized sexual and reproductive health services within the 12 months preceding the current survey. Being a first-year student $(\mathrm{AOR}=1.57$, 95\% CI: 1.01-2.46), having ever had sexual intercourse ( $\mathrm{AOR}=5.12,95 \% \mathrm{CI}: 3.31,7.96)$, participating in peer-to-peer discussion $(\mathrm{AOR}=1.46,95 \% \mathrm{CI}: 1.02-2.02)$, and having ever had sexual transmitted infection syndrome (AOR = 3.91, 95\% CI: 1.41-10.85) have increased the odds of using sexual and reproductive health services. Conclusion. Sexual and reproductive health services utilization among university students was inadequate and affected by several factors. Therefore, strengthening peer support networks and addressing the gap in services were highly recommended.
\end{abstract}

\section{Background}

Sexual and reproductive health is a state of complete physical, mental, and social well-being in all matters related to the reproductive system at all stages of life $[1,2]$. The United Nations International Conference on Population and Development (UNICPD) has grouped reproductive health within a broader sociocultural context that includes gender roles, respect, and protection of human rights [1].
Young people aged 15-24 experienced the highest rates of sexually transmitted infections of any age group in 2015 globally [2]. They also experience high rates of early and unintended pregnancy, unsafe abortion, and sexually transmitted infections including HIV [3]. Most importantly, the problem is becoming prevalent among youth in higher academic institutions $[4,5]$. It has been reported that students in higher academic institutions are more likely to be exposed to a range of risky sexual behaviours [6]. 


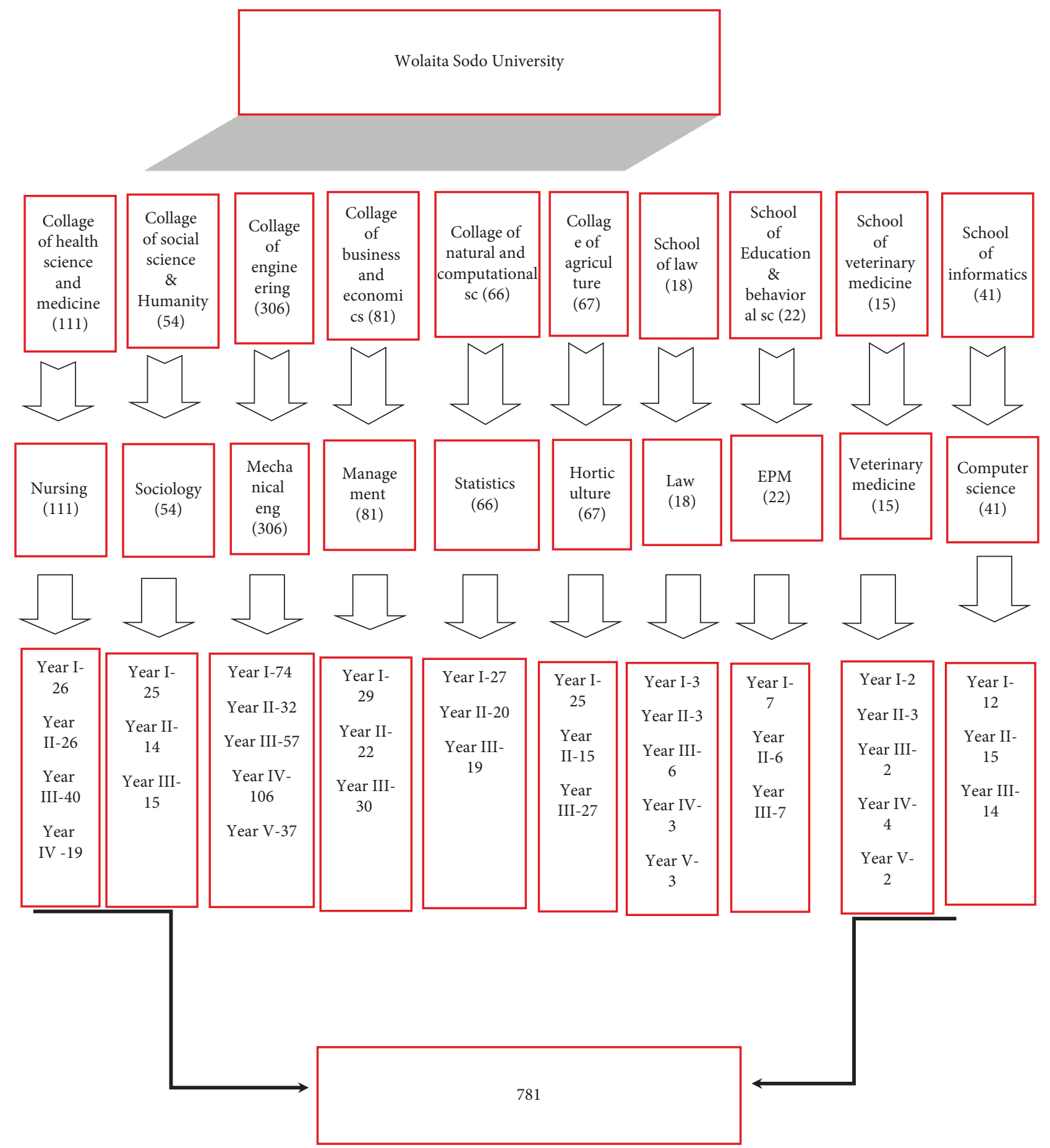

FIGURE 1: Schematic presentation of the sampling procedure to select study participants at WSU.

Estimates from the 2016 population demography of Ethiopia suggested that $33.8 \%$ of the population was in the age range of 10-24 years [7]. Although large numbers of youths in this age range are attending different universities within the country, significant numbers did not reach a full range of sexual and reproductive health services yet [4], indicating students have less access to information, services, and resources [8]. Thus, university students in Ethiopia often had low utilization of sexual and reproductive health services compared to the other groups of the population $[9,10]$.

To our knowledge, little has been investigated about sexual and reproductive health services utilization and their correlates in the context of Ethiopian higher education in general and Wolaita Sodo University in particular. Therefore, this study aimed to assess the prevalence of sexual and reproductive health service utilization and its associated 
factors among regular students attending Wolaita Sodo University, Ethiopia.

\section{Methods}

2.1. Study Setting and Design. An institutionally-based mixed-methods research approach was followed to conduct this study among Wolaita Sodo University students. Wolaita Sodo University is one of the second generation universities in Ethiopia, located $315 \mathrm{~km}$ away from Addis Ababa, the capital of Ethiopia.

2.2. Sample Size and Sampling Techniques. The sample size for this study was calculated by using a single population proportion formula with the assumption of a $95 \%$ confidence level, the margin of error of $5 \%$, and the prevalence of youth-friendly reproductive health service utilization (63.8\%), taken from a study of Harar, Ethiopia [11]. After considering a $10 \%$ nonresponse rate, the total sample size was estimated to be 781. Multistage random sampling and purposive sampling techniques have been used to recruit students for the quantitative and qualitative studies, respectively (Figure 1). The university had 12,092 regular undergraduate students in its six colleges and four schools. From each college and school, one department was selected by a lottery method. The proportional allocation method was used to choose study participants from each department. One class from each year of education was selected by a lottery method. A total of 37 classes were selected from randomly selected ten departments. Study participants were selected from the classes by using simple random sampling methods. For the qualitative study, the purposive sampling technique was employed to identify the list of potential indepth interview participants. A total of eleven key informant interviews were conducted with selected SRH service providers and students who were not included in the quantitative survey. Numbers of interviewees were sought out until idea saturation was reached.

2.3. Data Collection. A structured and self-administrated questionnaire was used for quantitative data collection. Data was collected by eight trained data collectors. Supervisors assigned students to classrooms and oriented students on how collected data will be handled. Questionnaires were stored in baskets which were prepared for the study purpose. The data collection process was closely supervised. A semistructured interview guide, notetaking, and tape recording were used to gather qualitative data. A trained data collector made the recording of audio data in quite a site with notetaking.

2.4. Data Processing and Analysis. We entered and cleaned the quantitative data by using EpiData version 3.1 and exported it to SPSS version 21 for analysis. We used descriptive statistics to calculate the frequencies and percentages of different variables. We used bivariate and multivariable logistic regression analyses along with the odds ratio and 95\% confidence intervals. Multivariable analysis was used to adjust for possible confounders and come up with significant predictors. The level of significance was declared at a $p$ value of less than 0.05 . In the qualitative part, the information recorded during data collection was first transcribed into hard copy documents. The transcription and notes taken in the field were translated into English. Coding and categorizing were done using OpenCode version 3.6 software. Finally, qualitative data were analyzed thematically.

2.5. Measurements. The knowledge score was computed based on four awareness questions (with "Yes"/"No" answers). Those who responded $0-2$ correct answers were categorized as "Not knowledgeable," while those who responded 3-4 correct answers were classified as "Knowledgeable." Attitude questions were measured using a Likert scale. But, to analyze the outcome variable, the composite variable was dichotomized using the median of the ten attitude questions. Those who scored less than or equal to the median score were categorized as having "Negative attitude." In contrast, those who scored more than the median score on attitude questions were classified as having "Positive attitude."

2.6. Operational Definition. SRH service utilization includes taking at least one of the following services like SRH counselling, condoms, abortion care, VCT, and family planning or STI treatment delivered at health facilities within the past 12 months (one year).

\section{Results}

A total of 759 students participated in this study, which made the response rate $97.2 \%$. Of 759 respondents, 411 $(54.2 \%)$ were males and $348(45.8 \%)$ were females. The median age of respondents was $21(\mathrm{IQR}=2)$. Regarding students' years of study, 188 (24.7\%) were in year one, 221 (29\%) were in year two, $192(25.3 \%)$ were in year three, and $158(21 \%)$ were in year four and above. The majority of 433 (57\%) of the respondents were orthodox, followed by Protestants 230 (30.3\%), Muslims 82 (10.8\%), and Catholics $14(1.9 \%)$ (Table 1$)$.

3.1. Sexual Behaviour and Discussion about SRH. Three hundred twenty (42.2\%) respondents said that they have a boy/girlfriend, and 224 (29.5\%) have ever had sexual intercourse in their lifetime. Of those who started sexual intercourse, $178(79.5 \%)$ stated that they had sexual intercourse within the last 12 months. More than half of the study participants $(413,54.4 \%)$ did not discuss with their parents about sexual and reproductive health issues, while $346(45.6 \%)$ discussed. The finding is triangulated by the qualitative part as "talking about sexuality and related issues with parents or elders is not common, fearing that our parents may assume as we are engaged in forbidden activities. It is considered as rudeness if we talk about sex- 
TABle 1: Sociodemographic characteristics of Wolaita Sodo University students, Southern Ethiopia, $2017(n=759)$.

\begin{tabular}{|c|c|c|c|}
\hline Variables & Category & Frequency & Percent \\
\hline \multirow{2}{*}{ Sex } & Male & 411 & 54.2 \\
\hline & Female & 348 & 45.8 \\
\hline \multirow{4}{*}{ Class year } & I & 188 & 24.7 \\
\hline & II & 221 & 29 \\
\hline & III & 192 & 25.3 \\
\hline & $\mathrm{IV}+$ & 158 & 21 \\
\hline \multirow{3}{*}{ Type of school attended (at preparatory) } & Governmental & 613 & 81 \\
\hline & Nongovernmental & 109 & 14 \\
\hline & Both & 37 & 5 \\
\hline \multirow{4}{*}{ Religion } & Orthodox & 433 & 57 \\
\hline & Muslim & 82 & 10.8 \\
\hline & Protestant & 230 & 30.3 \\
\hline & Catholic & 14 & 1.9 \\
\hline \multirow{2}{*}{ Marital status } & Never married & 721 & 95 \\
\hline & Ever married & 38 & 5 \\
\hline \multirow{2}{*}{ The place for getting meal service } & University cafeteria & 479 & 63.1 \\
\hline & Outside university & 280 & 36.9 \\
\hline \multirow{5}{*}{ Mother's occupation } & Formal employment & 124 & 16.3 \\
\hline & Daily labourer & 8 & 1.2 \\
\hline & Self-employed/business & 165 & 21.7 \\
\hline & Farmer & 124 & 16.3 \\
\hline & House wife & 338 & 44.5 \\
\hline \multirow{4}{*}{ Father's occupation } & Formal employment & 259 & 34.1 \\
\hline & Casual labourer & 19 & 2.5 \\
\hline & Self-employed/business & 175 & 23.1 \\
\hline & Farmer & 306 & 40.3 \\
\hline \multirow{2}{*}{ Parents place of residence } & Rural & 412 & 54.3 \\
\hline & Urban & 347 & 45.7 \\
\hline
\end{tabular}

TABLE 2: Sexual behaviour and discussion about sexual and reproductive health issues among Wolaita Sodo University students, Southern Ethiopia, $2017(n=759)$.

\begin{tabular}{|c|c|c|c|}
\hline Variables & Category & Frequency & Percent \\
\hline \multirow{2}{*}{ Have a boyfriend/girlfriend } & Yes & 320 & 42.2 \\
\hline & No & 439 & 57.8 \\
\hline \multirow{2}{*}{ Ever had sexual intercourse } & Yes & 224 & 29.5 \\
\hline & No & 535 & 70.5 \\
\hline \multirow{2}{*}{ First sex consented } & Yes & 172 & 22.7 \\
\hline & No & 52 & 6.8 \\
\hline \multirow{3}{*}{ Number of sexual partners ever had } & One & 106 & 14 \\
\hline & Two & 57 & 7.5 \\
\hline & More than two & 61 & 8 \\
\hline \multirow{5}{*}{ The last time had sex } & Within the last week & 33 & 4.3 \\
\hline & Within the last month & 51 & 6.7 \\
\hline & Within the last six months & 57 & 7.5 \\
\hline & Within the last year & 37 & 4.9 \\
\hline & More than one year ago & 46 & 6 \\
\hline \multirow{2}{*}{ Ever discussed with parents about SRH issues } & Yes & 346 & 45.6 \\
\hline & No & 413 & 54.4 \\
\hline \multirow{2}{*}{ Ever participated in peer-to-peer education programs } & Yes & 362 & 47.7 \\
\hline & No & 397 & 52.3 \\
\hline \multirow{2}{*}{ Ever had signs of STIs } & Yes & 47 & 7.2 \\
\hline & No & 712 & 93.8 \\
\hline
\end{tabular}

related issues in front of father or mother in our home" $(22-$ year-old male student) (Table 2).

3.2. Knowledge and Attitude of Students on Sexual and Reproductive Health. From a total of 759 respondents, 639 $(84.2 \%)$ heard of sexual and reproductive health services.
About $632(83.3 \%)$ of the study participants were knowledgeable about sexual and reproductive health issues. Regarding the attitude towards sexual and reproductive health, $372(49 \%)$ of the respondents had a positive attitude, while the majority of the study participants $(387,51 \%)$ had a negative attitude (Table 3 ). 
TABLE 3: Knowledge and attitude of Wolaita Sodo university students about sexual and reproductive health-related issues, Southern Ethiopia, $2017(N=759)$.

\begin{tabular}{|c|c|c|c|}
\hline Variables & Category & Frequency & Percent \\
\hline \multirow{2}{*}{ Knowledge about sexual and reproductive health issues } & Knowledgeable & 632 & 83.3 \\
\hline & Not knowledgeable & 127 & 16.7 \\
\hline \multirow{2}{*}{ Ever heard of sexual and reproductive health services } & Yes & 639 & 84.2 \\
\hline & No & 120 & 15.8 \\
\hline \multirow{2}{*}{ Know any family planning methods } & Yes & 681 & 89.7 \\
\hline & No & 78 & 10.3 \\
\hline \multirow{2}{*}{ Ever heard about sexually transmitted infections } & Yes & 669 & 88.1 \\
\hline & No & 90 & 11.9 \\
\hline \multirow{2}{*}{ Know methods for preventing STIs } & Yes & 596 & 78.5 \\
\hline & No & 163 & 21.5 \\
\hline \multirow{2}{*}{ Attitude towards SRH service utilization } & Positive attitude & 372 & 49 \\
\hline & Negative attitude & 387 & 51 \\
\hline
\end{tabular}

3.3. Preference of Health Facilities and Sources of Information about SRH Services. Only 83 (10.9\%) of study participants prefer university clinics to receive sexual and reproductive health services. A qualitative study also confirmed that the sexual and reproductive health services delivered at a university clinic do not satisfy students. "There is a contrasting pattern in reproductive health services delivery between the university clinic and private/community-based facilities. The service delivered at the university clinic has a lot of gaps, and it lacks most of the services we seek" (23-year-old female respondent). About 348 (45.8\%) had received information about sexual and reproductive health from their friends. The finding from the qualitative part also showed that "...All that I know about sexual and reproductive health is from my friends or health care providers and sometimes from an advertisement on radio and TV. Based on this source, I try to understand the reproductive health services in health facilities that are available for youths like me" (21year-old male student).

3.4. Utilization of Sexual and Reproductive Health Services by University Students. Of the total of 759 study participants, $378(49.8 \%)$ utilized reproductive health services in the year before the survey. Family planning, voluntary counselling and testing of HIV, treatment for STIs, counselling on SRH, condoms, and abortion were utilized by $94(12.4 \%), 289$ (38.1\%), 34 (4.5\%), 131 (17.3), 112 (14.8\%), and $11(1.4 \%)$ of students, respectively. Among sexually active respondents, $182(81.3 \%)$ have utilized at least one of the sexual and reproductive health services within the past twelve months.

3.5. Factors Associated with Sexual and Reproductive Health Service Utilization among Wolaita Sodo University Students. According to the results of the bivariate analysis, thirteen variables were associated with the utilization of sexual and reproductive health services. In the final model (multivariable analysis), the result indicated that being a first-year student, having sexual intercourse, participating in peer-to-peer discussion, and having STI syndrome were found to be significant factors associated with sexual and reproductive health service utilization (Table 4).

\section{Discussion}

This study was conducted to investigate the prevalence of sexual and reproductive health service utilization and its associated factors among Woliata Sodo university students in Ethiopia. The level of SRH service utilization was found to be $49.8 \%$. The finding of the current study was higher than some previous studies conducted in Awobel district (41.2\%) [12], Mizan Tepi University (24.5\%) [13], Hadiya zone (38.5\%) [14], Bahir Dar (32\%) [5], Jimma [15], and Nepal (9.2\%) [16]. The discrepancy in the prevalence estimate may be explained by the variation in the study settings. For example, the majority of the aforementioned studies have been conducted among secondary and high school students, whereas our study was conducted at the university which might play a role in the observed discrepancy. It is believed that university students could have a better understanding of $\mathrm{SRH}$ issues and such services are more accessible to them as compared to high school students. Therefore, the availability and accessibility of services may play a significant role in the observed variation in the prevalence estimate. However, the prevalence of SRH service utilization in our study was lower than the prevalence estimates from the studies conducted in Madawalabu University (80.5\%) [10] and Harar town (64\%) [11]. This may be due to the difference in the definition of SRH service utilization and the settings of the study. The study conducted at Madawalabu University assessed the utilization of SRH services, whereas the current study assessed utilization within one year.

In this study, being a first-year university student was associated with sexual and reproductive health service utilization. Our finding was in agreement with the findings from Madawalabu University [10]. This may be attributed to changing trends in the early development of sexual maturity and increased demand for sexual and reproductive health care [17]. Nonetheless, a study conducted in Goba town observed contrasting results [18].

Ever having sex is another factor associated with sexual and reproductive health service utilization. The current 
TABLE 4: Bivariate and multivariable analyses showing factors associated with SRH service utilization among Wolaita Sodo University students, Southern Ethiopia, 2017.

\begin{tabular}{|c|c|c|c|c|c|}
\hline \multirow[t]{2}{*}{ Variables } & \multirow[t]{2}{*}{ Category } & \multicolumn{2}{|c|}{$\begin{array}{c}\text { SRH service } \\
\text { utilization }\end{array}$} & \multirow[t]{2}{*}{ COR 95\% CI } & \multirow[t]{2}{*}{ AOR 95\% CI } \\
\hline & & No & Yes & & \\
\hline \multirow{2}{*}{ Sex } & Male & 184 & 227 & 1 & 1 \\
\hline & Female & 197 & 151 & $0.62[0.46-0.83]$ & $0.79[0.54-1.16]$ \\
\hline \multirow{3}{*}{ Age } & $17-20$ & 187 & 172 & $0.87[0.65-1.16]$ & $0.81[0.54-1.22]$ \\
\hline & $21-24$ & 186 & 197 & 1 & 1 \\
\hline & $25+$ & 8 & 9 & 1.06 [0.40-2.81] & $0.74[0.23-2.36]$ \\
\hline \multirow{4}{*}{ Class year } & I & 85 & 103 & 1.52 [1.03-2.25] & $1.71[1.10-2.69]^{*}$ \\
\hline & II & 123 & 98 & 1 & 1 \\
\hline & III & 85 & 107 & 1.58 [1.07-2.33] & $1.34[0.85-2.13]$ \\
\hline & $\mathrm{IV}+$ & 88 & 70 & $0.99(0.66-1.51]$ & $1.06[0.62-1.81]$ \\
\hline \multirow{2}{*}{ Marital status } & Ever married & 8 & 30 & $4.02[1.82-8.89]$ & $1.76[0.69-4.51]$ \\
\hline & Never married & 373 & 348 & 1 & 1 \\
\hline \multirow{2}{*}{ Place for getting meal service } & University cafeteria & 220 & 259 & 1 & 1 \\
\hline & Outside university & 161 & 119 & $0.63[0.47-0.85]$ & $0.71[0.46-1.08]$ \\
\hline \multirow{3}{*}{ Monthly pocket money } & $100-500$ & 304 & 296 & 1 & 1 \\
\hline & $501-1000$ & 72 & 64 & $0.27[0.10-0.74]$ & $0.79[0.50-1.23]$ \\
\hline & $1001+$ & 5 & 18 & $0.25[0.09-0.70]$ & $2.47[0.83-7.33]$ \\
\hline \multirow{2}{*}{ Have a boyfriend/girlfriend } & Yes & 131 & 189 & $1.91[1.43-2.56]$ & $1.29[0.91-1.86]$ \\
\hline & No & 250 & 189 & 1 & 1 \\
\hline \multirow{2}{*}{ Ever had sexual intercourse } & Yes & 42 & 182 & $7.50[5.13-10.95]$ & $5.12[3.33-7.90]^{* * *}$ \\
\hline & No & 339 & 196 & 1 & 1 \\
\hline \multirow{2}{*}{ Parental discussion on SRH issues } & Yes & 152 & 194 & $1.58[1.19-2.12]$ & $1.24[0.87-1.75]$ \\
\hline & No & 229 & 184 & 1 & 1 \\
\hline \multirow{2}{*}{ Participated in peer-to-peer education } & Yes & 152 & 210 & $1.88[1.41-2.51]$ & $1.48[1.05-2.10]^{*}$ \\
\hline & No & 229 & 168 & 1 & 1 \\
\hline \multirow{2}{*}{ Attitude towards SRH services } & Positive & 195 & 177 & $0.84[0.63-1.12]$ & $1.02[0.74-1.42]$ \\
\hline & Negative & 186 & 201 & 1 & 1 \\
\hline \multirow{2}{*}{ Ever had signs of STIs } & Yes & 5 & 42 & $9.40[3.68-24.04]$ & $3.55[1.30-9.80]^{*}$ \\
\hline & No & 376 & 336 & 1 & 1 \\
\hline
\end{tabular}

${ }^{*} P<0.05,{ }^{* * *} P<0.001$, AOR: adjusted odds ratio, and COR: crude odds ratio.

finding is in line with results from Madawalabu University [10]. Unlike the finding from the study conducted in the North Shewa Zone [19], the observation of our study was also consistent with the findings of other similar studies from Ethiopia $[12,14]$. This might be due to those students who have ever had sexual intercourse needing relevant services to avoid the risk and consequences of sexual vulnerability.

Participating in peer-to-peer education is also associated with sexual and reproductive health service utilization. This finding matches with results from Madawalabu University [10], Goba town [20], Awobel district [12], and West Badewacho district [21]. The likely explanation could be that discussion about sexual and reproductive health issues helps to create awareness of the benefits of SRH services.

Having ever had STI syndrome is also another factor associated with the utilization of sexual and reproductive health services. This finding agrees with findings from a study conducted in Bahir Dar and Hadiya Zone $[8,14]$. This might be due to students who had SRH problems and needed further assistance to avoid the risk and consequences of sexual vulnerability.

Among the limitations of the study, the cross-sectional nature of the study may not show the temporal relationship between the outcome and the independent variables. The current study assessed the sensitive issues related to sexuality that might have caused social desirability bias, and this may underestimate or overestimate an outcome of interest. Some of the issues raised about the sexual behaviour of participants explored the past practices of the students, which can also be affected by recall bias. Thus, the findings of this study should be interpreted with these limitations.

\section{Conclusion}

This study aims to examine sexual and reproductive health service utilization among university students and to explore the barriers to utilizing reproductive health services by university students. Even though students have good knowledge and information about sexual and reproductive health services, the utilization of their services is low, which indicates that a high level of $\mathrm{SRH}$ knowledge is not translating into significant behaviour change. Being a firstyear student, having ever had sexual intercourse, participating in peer-to-peer discussion, and having STI syndrome were predictors of SRH service utilization. Encouraging peer support networks and establishing another integrative and comprehensive approach to improve the current reproductive health status of university students is vital. 


\section{Abbreviations}

HIV: Human immunodeficiency virus

ICPD: International Conference on Population and Development

SRH: Sexual and reproductive health

STIs: Sexually transmitted infections.

\section{Data Availability}

The data used to support the findings of this study are included within the article.

\section{Ethical Approval}

The authors obtained ethical clearance from the Ethical Review Committee of the College of Health Sciences and Medicine, Wolaita Sodo University, Ethiopia. An official letter of cooperation was written to every college and school in the university. Permission letters were obtained from colleges and schools. The way they were selected and the purpose of the study were fully explained. The authors received written informed consent from the participants for possible ethical considerations and the verbal informed consent for ethics approval and consent to participate. The participant's informed consent included the publication of interview quotes.

\section{Consent}

Not applicable.

\section{Conflicts of Interest}

The authors declare that they have no conflicts of interest.

\section{Authors' Contributions}

All the authors made a significant contribution to this work. They took part in study design, data analysis and interpretation, drafting, revising or critically reviewing the article, gave final approval of the version to be published, and agreed to be accountable for all aspects of the work. All authors read and approved the final manuscript.

\section{Acknowledgments}

The authors want to acknowledge Wolaita Sodo University and Wolaita Zone Health Department for their support to this study. The authors also like to extend their gratitude to study participants, data collectors, and supervisors. Wolaita Zone Health Department, Ethiopia, has funded this research.

\section{References}

[1] UNPF, Programme of Action of the International Conference on Population and Development, UNPF, New York, NY, USA, 2018, https://www.unescap.org/resources/programmeaction-international-conference-population-anddevelopment.
[2] UNPFA, Sexual and Reproductive Health of Young People in Asia and the Pacific 2015 Burnet Institute victoria, Australia, New York, NY, USA, 2018, https://asiapacific.unfpa.org/sites/ default/files/pub-pdf/SRH\%20of\%20Ummarried\%20Young\% 20People\%20in\%20Asia\%20Pacific.

[3] CSA, Ethiopia Mini Demographic and Health Survey, CSA, Longueuil, Quebec, 2014, https://scholar.google.com/scholar? $\mathrm{q}=7 .+\mathrm{CSA},+$ Ethiopia+Mini+Demographic + and + Health + Survey+2014.\&hl=en\&as_sdt=0\&as_vis $=1 \&$ oi $=$ scholart.

[4] B. S. Gemechu Kejela and G. Kejela, "Assessment of risky sexual behaviors among arba minch university students, arba minch town, snnpr, Ethiopia," Journal of Child and Adolescent Behavior, vol. 3, no. 2, p. 189, 2015.

[5] M. Abebe and W. Awoke, "Utilization of youth reproductive health services and associated factors among high school students in Bahir dar, Amhara regional state, Ethiopia," Open Journal of Epidemiology, vol. 4, no. 2, pp. 69-75, 2014.

[6] CSA, Ethiopia Demographic and Health Survey, Addis Ababa, Ethiopia, 2016, https://scholar.google.com/scholar?q=11. +CSA:+Ethiopia+Demographic+and+Health+Survey+2016+ Addis + Ababa, + Ethiopia\&hl=en\&as_sdt=0\&as_ vis $=1 \&$ oi $=$ scholart.

[7] D. Bayissa, G. Mebratu, G. Bayisa, and Y. Mekuanint, “Assessment of early sexual initiation and associated factors among ambo university undergraduate students, ambo, Ethiopia," Journal of Contraceptive Studies, vol. 29, p. 1, 2016.

[8] Y. M. Adinew, A. G. Worku, and Z. B. Mengesha, "Knowledge of reproductive and sexual rights among University students in Ethiopia: institution-based cross-sectional," BMC International Health and Human Rights, vol. 13, no. 1, p. 12, 2013.

[9] N. Dida, B. Darega, and A. Takele, "Reproductive health services utilization and its associated factors among Madawalabu University students, Southeast Ethiopia: cross-sectional study," BMC Research Notes, vol. 8, no. 1, p. 8, 2015.

[10] T. Dingeta, L. Oljira, and N. Assefa, "Patterns of sexual risk behavior among undergraduate university students in Ethiopia: a cross-sectional study," The Pan African medical journal, vol. 12, p. 33, 2012.

[11] B. Gebreselassie, "Assessment of reproductive health service utilization and associated factors among adolescents (15-19 Years old) in Goba town, southeast Ethiopia," American Journal of Health Research, vol. 3, no. 4, pp. 203-212, 2015.

[12] A. Ayehu, T. Kassaw, and G. Hailu, "Level of young people sexual and reproductive health service utilization and its associated factors among young people in awabel district, northwest Ethiopia," PLoS One, vol. 11, no. 3, Article ID e0151613, 2016.

[13] A. Motuma, T. Syre, G. Egata, and A. Kenay, "Utilization of youth friendly services and associated factors among youth in Harar town, east Ethiopia: a mixed method study," BMC Health Services Research, vol. 16, no. 1, p. 272, 2016.

[14] Y. Yemaneh, R. Gezahagn, M. Yechale, M. Assefa, and K. Abrha, "Assessment of knowledge, attitude and practice towards reproductive health service among mizan Tepi universtiy Tepi campus students, sheka zone, south Nations nationalities and peoples regional state, south west Ethiopia, 2017," J Hosp Med Manage, vol. 3, no. 1, p. 11, 2017.

[15] A. Tegegn and Y. Gelaw, "Adolescent reproductive health services in Jimma city: accessibility and utilization," Ethiopian Journal of Health Sciences, vol. 19, no. 2, 2009.

[16] K. Bam, "Perceived sexual and reproductive health needs and service utilization among higher secondary school students in urban Nepal," American Journal of Public Health Research, vol. 3, no. 2, pp. 36-45, 2015. 
[17] D. Helamo, S. Kusheta, B. Bancha, Y. Habtu, and S. Yohannes, "Utilization and factors affecting adolescents and youth friendly reproductive health services among secondary school students in Hadiya zone, southern Nations, nationalities and peoples region, Ethiopia," International Journal of Public Health Science, vol. 2, p. 141, 2017.

[18] W. Negash, M Dessalegn, B Yitayew, M Demsie, M Wagnew, and J Nyagero, "Reproductive health service utilization and associated factors: the case of north Shewa zone youth, Amhara region, Ethiopia," The Pan African Medical Journal, vol. 25, no. Supp 2, p. 3, 2016.

[19] A. Gurure, T. Markod, and J. Abrar, "Youth friendly sexual and reproductive health services utilization and associated factors among school youths in Goba town, bale zone, southeast Ethiopia," European Journal of Biomedical and Pharmaceutical Sciences, vol. 4, no. 3, 2017.

[20] T. Susanto, "Prevalence of factors related to active reproductive health behavior: a cross-sectional study Indonesian adolescent," Epidemiology and Health, vol. 8, p. 10, 2016.

[21] N. Cherie, G. Tura, and N. T. Aderajew, "Reproductive health needs and service utilization among youths in Badewacho Woreda, Hadiya Zone, South Ethiopia," Journal of Public Health and Epidemiology, vol. 7, 2015. 